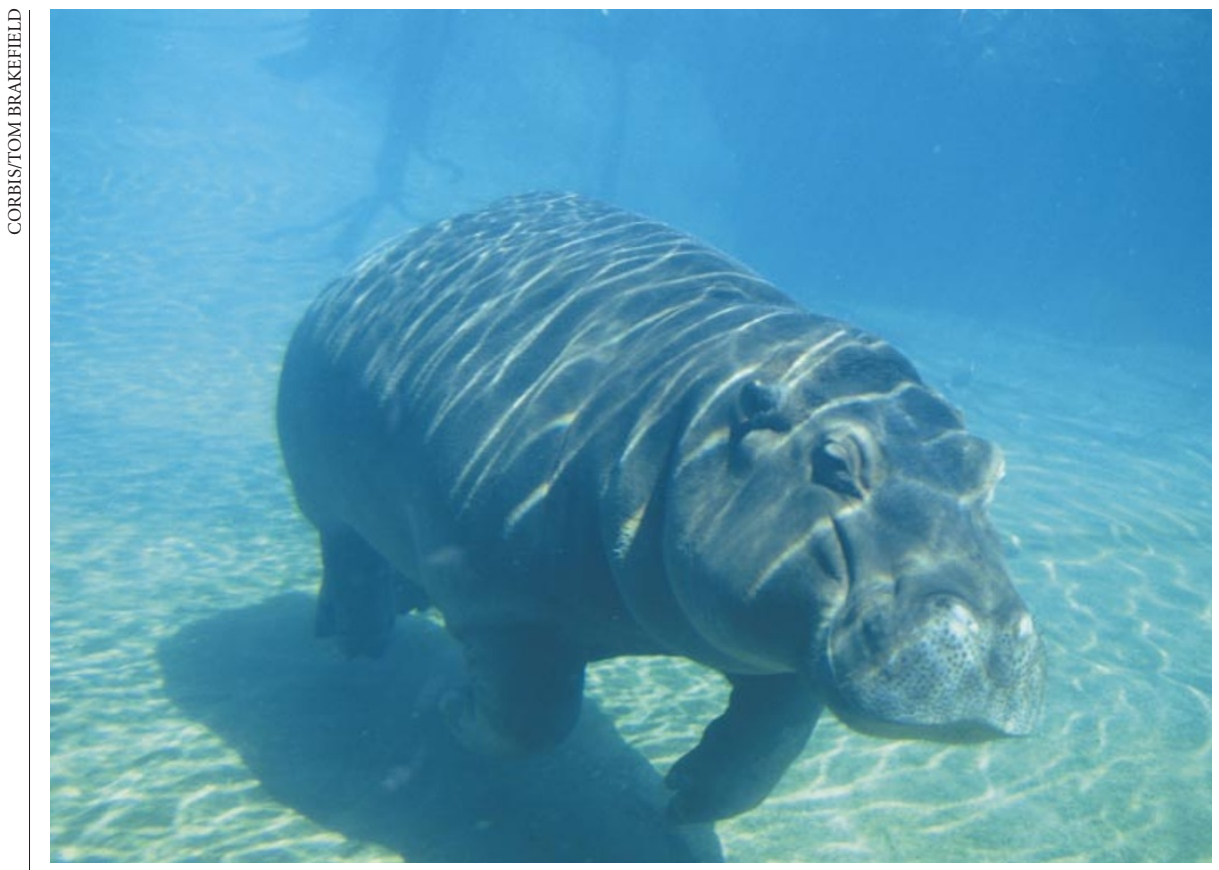

Almost like a whale: the hippopotamus is the whale's closest living relative.

(one species descending from another). Indeed, so conventional has Darwin become that even the Pope accepts the reality of evolution, although he shrewdly insists that souls are outside its reach.

Steve Jones equally shrewdly realizes that all this makes Origin of Species a good candidate for the book of the millennium - a view others share. It may come as a surprise, then, to learn that he has chosen to rewrite it. Is this the scientific rationalist's variation on blasphemy? Jones thinks not, suggesting that, although no one ever put the case for 'evolution' better than Darwin (ironically, Darwin avoided that word, using it only once in the Origin), the facts in the Origin "are those of a century and a half ago and leave many gaps before its case can be considered proven". Reverently, Jones retains and uses as his own framework Darwin's chapter titles, chapter summaries, lists of chapter contents and, curiously, all of Darwin's final chapter. The title is his own, although it, too, derives from a line in the Origin.

Jones's opening remarks cite the familiar refrain of the "100 million Americans" who believe that "God created man pretty much in his present form at one time during the last ten thousand years". In fact, even this represents progress for the theory: these same 100 million people have been quoted since I was a boy, when they made up nearly 50 per cent of the US population. Now there are something like 280 million Americans.

Most of the book's introductory chapter, however, is devoted to the AIDS virus. Jones observes that "the human immunodeficiency virus contains in its brief history the entire argument of The Origin of Species". And so it does. Research on HIV reveals its struggle for existence, the action of natural selection, its

geographical spread and descent with modification. How much more about evolution and adaptation must be known if other organisms are included? In succeeding chapters, Jones moves on to these other organisms, and draws on a prodigious inventory of facts to support Darwin's original musings on 'variation under domestication', 'difficulties of the theory', the 'imperfection of the geological record', 'hybridism' and more.

Imagine Darwin's delight had he known that hippopotamuses are the closest living relatives to the whales, or that Arctic and Antarctic fishes have independently evolved anti-freeze, or that some insects got their wings from the gills of other insects. Where Darwin, of course, had no knowledge of or access to genetic information, Jones reports many of the latest charms of evolutionary genetics, such as horizontal gene transfer, selfish DNA and genome mapping projects. All this is reported in his staccato style, suitable for the general reader and yet informative for the specialist. He is seldom more than a paragraph away from some amusing or thought-provoking anecdote: the allegations about George Spencer and a one-eyed pig are memorable.

Jones is sceptical about much of the work that applies principles of natural selection to understanding human social evolution and behaviour: human sociobiology. Darwin, whose The Descent of Man - and Selection in Relation to Sex remains startlingly bold and perspicacious in doing just that, would not, I think, approve. True, some human sociobiological studies border on the crude and offensive. Others, however, are producing some of the most challenging and stimulating work in evolutionary biology. Humans are to some extent the final frontier, always until now pro- tected from the vulgar apparatus of biological evolution by intelligence and cultural innovation. But demonstrations that cultural practices, including wealth inheritance and marital systems, family size and differential investment in children, are explicable on darwinian grounds have demolished the view of humans as above the fray.

Nevertheless, Jones remains one of our most effective commentators and writers on science. Almost Like a Whale, at around 400 thick pages, is almost like a whale to carry around. But it repays the effort. This 'Origin of Species - Revised Edition' may lack the sense of danger and discovery of its predecessor, and the radicalism has been replaced by a presumption of the truth of natural selection. Yet Jones succeeds impressively in his desire to bring us up to date on the facts of evolution: to read this book is to see in one place much of the sweep and grandeur of evolution by natural selection.

Mark Pagel is at the School of Animal and Microbial Sciences, University of Reading, Whiteknights, Reading RG6 6AJ, UK.

\section{Coelacanth à la Marseillaise}

\section{A Fish Caught in Time: The Search for the Coelacanth \\ by Samantha Weinberg \\ Fourth Estate: 1999. 239 pp. $£ 13.99$ \\ Philippe Janvier}

In December 1938, the first living coelacanth (Latimeria chalumnae) to become known to science was accidentally caught near East London in South Africa. Coelacanths were thought to have been extinct for 70 million years - since the late Cretaceous - hence the sensational impact of this discovery of a 'living fossil'. But, in addition to this astonishing survival, the coelacanth revealed the anatomy of the soft tissues of 'crossopterygian' fishes, thought to have been forerunners of the four-legged vertebrates, or tetrapods. Therefore, it raised considerable interest among evolutionary biologists and palaeontologists. Samantha Weinberg's book describes the history of the discovery of the living coelacanth, and the lives of the women and men involved in it.

Several books have been published previously on the story of the Comoran coelacanth, including Old Fourlegs by J. L. B. Smith (Longmans, 1956), who first described the fish and named it after its discoverer, Marjorie Courtenay-Latimer. But Weinberg's book also includes the account of the recent discovery of the Indonesian coelacanth. In her book, both discoveries sound like detec- 
tive stories, with obscure political and ethical intrigues, often involving French scientists.

The first coelacanth was mounted in such a way that little of its anatomy was available to Smith, who was eagerly waiting for a second specimen. Thanks to Eric Hunt, the second coelacanth turned up in 1952, but in the Comoros. The way it was taken from the Comoros, then a French colony, by Smith himself, on board a plane chartered by South Africa's prime minister, Daniel Malan, raised frustration among French scientists and led the French government to ban foreign coelacanth investigators. Subsequently, most coelacanths caught in the Comoros were sent to Paris and then either used for anatomical study or donated to major scientific institutions, with the stipulation that they would not be dissected.

Smith accused the French of hindering the scientific study of this extraordinary fish, and appealed, in vain, to an international research programme. Weinberg clearly sympathizes with Smith on this matter. Alas, generosity is rare when a country possesses an invaluable research subject. In 1952, French science was recovering from the war and the sudden discovery of the coelacanth in French waters could not possibly be ignored. Whatever judgement one may pass on the appropriation of the coelacanth by the French, or, conversely, on the cavalier expedition of Hunt and Smith, the resulting monographs on the anatomy of Latimeria, by J. Millot and J. Anthony (and D. Robineau for the last volume), remain a masterpiece. Nevertheless, many French zoologists felt that Smith should have been closely involved in the anatomical study of the fish. After all, neither Millot

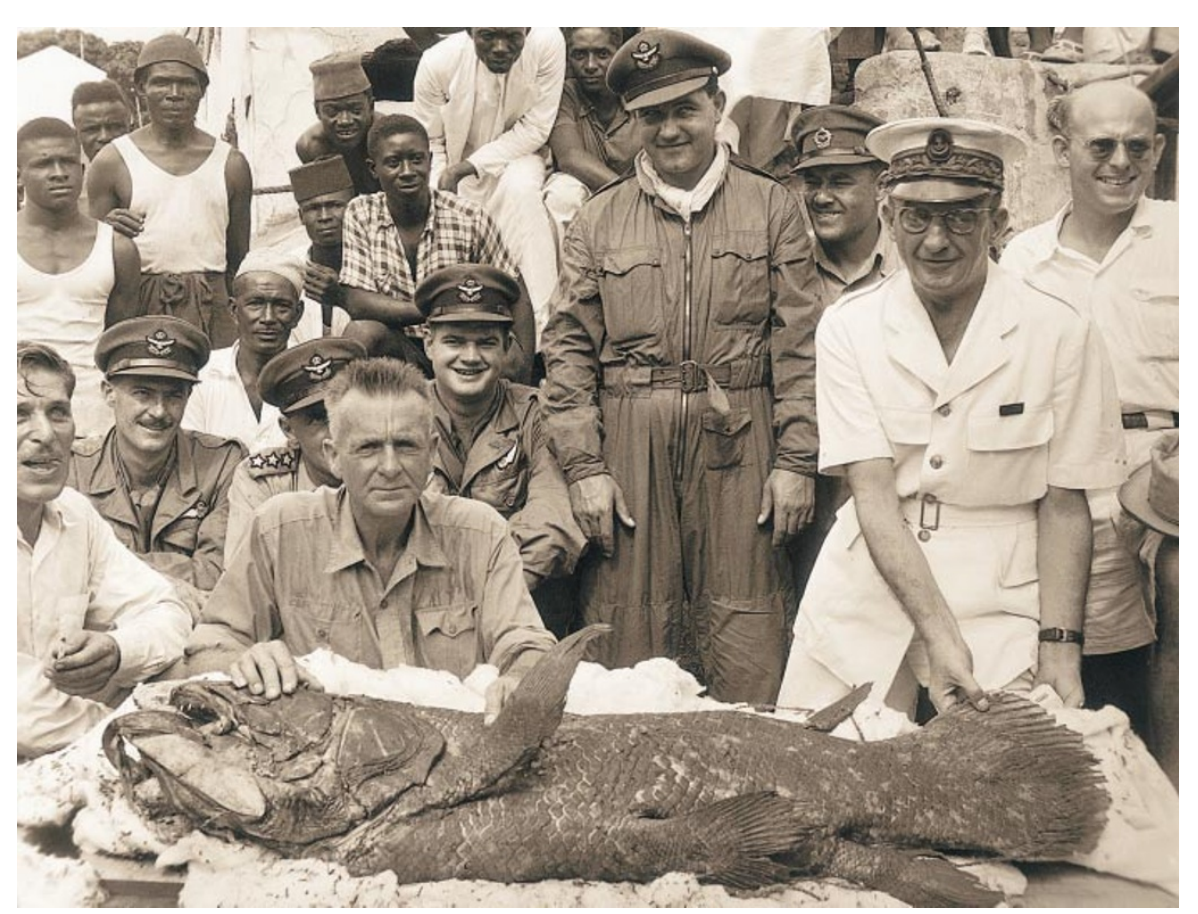

Resting in peace: Smith's hand lies on the head of the second coelacanth found off the Comoro Islands.

nor Anthony were initially ichthyologists, whereas Smith was in 1952, at any rate.

The discoverer of the Indonesian coelacanth, Mark Erdmann, had a radically different attitude from Smith's, as he immediately donated the first specimens to an Indonesian institution and established an agreement for a US-Indonesian joint study of the specimen, in particular a molecular sequence study to check whether it is the same species as the Comoran coelacanth. All went smoothly, and the discovery of the Indonesian coelacanth appeared in Nature (395, 335 ; 1998) in September 1998. Mark and Arnaz Erdmann were heroes, as CourtenayLatimer and Smith had been in 1939, but with, in addition, a fairy-tale atmosphere because this latest discovery was made during the young couple's honeymoon.

Then, in April 1999, came the shock: the French, "inevitably" (in Weinberg's words), published a paper aimed at giving a scientific name to the Indonesian coelacanth $(L$. menadoensis, after Menadotua Island, where it was caught) on the basis of a quick morphological and molecular sequence analysis that suggested some difference from $L$. chalumnae. In fact, the authors of this note are both French and Indonesian, with Laurent Pouyaud (not Pouyard) as the first and only French author. Apparently, the Indonesian authorities gave them free access to samples from the specimen donated by the Erdmanns. To play devil's advocate, one may say that the Indonesians did exactly what Smith wanted the French to do. Unfortunately, this new page of the eventful history of the coelacanth came too late to be dealt with in detail by Weinberg, and is only accounted for in a justifiably angry footnote.

NATURE|VOL 401 | 28 OCTOBER 1999 | www.nature.com
The naming of the Indonesian coelacanth is at odds with the ethics of systematics: no reference to the discoverer of the specimen (notoriously studying it), no designation of the holotype (admittedly, a single specimen to date), no museum number and, above all, a wide spreading of the new name in the press before the scientific publication appeared. Immediately, heated debates occurred among systematicians as to whether the name was acceptable, or should have the authorship of the first journalist who published it in a daily newspaper, instead of that of Pouyaud and his co-authors. But, according to the requirements of the current edition of the International Code of Zoological Nomenclature, there seems to be no reason to reject it and its authorship, whatever its ethically questionable background. Further studies, however, may prove $L$. menadoensis to be a mere synonym of $L$. chalumnae. The close collaboration between the German Hans Fricke and the French Raphael Plante in the first successful observations of the Comoran coelacanth alive and well in its natural environment contrasts greatly with the history of the naming of the Indonesian one.

Weinberg explains why the coelacanth is interesting and at the same time disappointing, in the context of the question of the origin of tetrapods. She also gives an account of the discovery of the lungfishes, in the nineteenth century, which raised the same excitement as that of Latimeria. However, this section and the section about fossils contain a few minor mistakes (for example, the spiral valve is not in the stomach, but in the intestine). The coelacanth is currently classified among the sarcopterygians (vertebrates in which the paired fin/limbs skeleton articulates to the girdles by means of a single bone, the humerus and the femur in tetrapods). Along with lungfishes, the tetrapods and several fossil-fish groups, it shares very few advanced characters with the tetrapods, and this puts it somewhere near the base of the sarcopterygian tree. In a sense, the coelacanth tells us more about the primitive condition of all bony fishes than about the origin of tetrapods.

As a whole, the book reads well, like an adventure story, with amusing and charming anecdotes about the lives of the protagonists. To a scientist, it may be frustrating not to read more about how palaeontologists reacted to the discovery of Latimeria and how it could test their previous reconstructions. Although, admittedly, most palaeontologists who dealt with coelacanths and other fossil sarcopterygians before 1938 and experienced the pre- and post-Latimeria times are now dead, very few have written about this.

The conclusion of the book somewhat tails off. It mentions the possibility of finding more coelacanths elsewhere in the world, which is plausible, and the need to protect and "leave the coelacanth in peace", which is

NATURE|VOL 401|28OCTOBER 1999| www.nature.com 
wise. Nevertheless, the author should perhaps have questioned scientists about what more they expect from this fish. Its behaviour is barely known and, above all, its embryonic development is totally unknown. Knowing how the strangely articulated braincase or the fins of the coelacanth develop would be just as important as what we already know of its anatomy, in particular for understanding the early evolution of bony fishes and sarcopterygians. This is perhaps the next challenge for the forthcoming century.

Lay readers will certainly enjoy A Fish Caught in Time, but it can also be recommended to students and zoologists who are too young to have experienced this extraordinary zoological adventure.

Philippe Janvier is at the Laboratoire de

Paléontologie, Muséum National d'Histoire

Naturelle, 8 rue Buffon, 75005 Paris, France.

\section{Pogo-centricity}

Ants at Work: How an Insect

\section{Society is Organized}

by Deborah Gordon

Free Press: 1999.208 pp. $\$ 25$

\section{Jürgen Heinze}

It is certainly an odd sight in the early light of an Arizona desert morning to see a number of people digging themselves into the dry soil, crawling around with their noses close to the ground, hunting for something that is invisible from even a short distance. Still, the inhabitants of Paradise and Portal in southeasternmost Arizona are by now presumably quite used to it, because over the past decades the Chiricahua Mountains and adjacent San Simon Valley have become a favourite field site for researchers interested in the evolution, sociobiology and ecology of ants. One of them, Stanford professor Deborah Gordon, now writes about what she has discovered, in 17 years of observations, lab and field experiments and computer modelling, about Pogonomyrmex harvester ants.

Ants at Work is an entertaining mixture of personal travel report and popular science. And it is deliberately 'Pogo-centric', as the author herself says: it focuses almost exclusively on this genus, ignoring most other ants. It is also much more a private, 'Gordoncentric' oeuvre than a comprehensive and integrated treatise on ants, and three-quarters of the roughly 45 references in the appendix are by the author and her research team. Other research on Pogonomyrmex, including studies done just across the road from her own study site and a recently published book on harvester-ant biology, is left aside, as are other key publications, including several fundamental reviews on ant biology. These omissions might perhaps help a naive reader, whose knowledge does not go

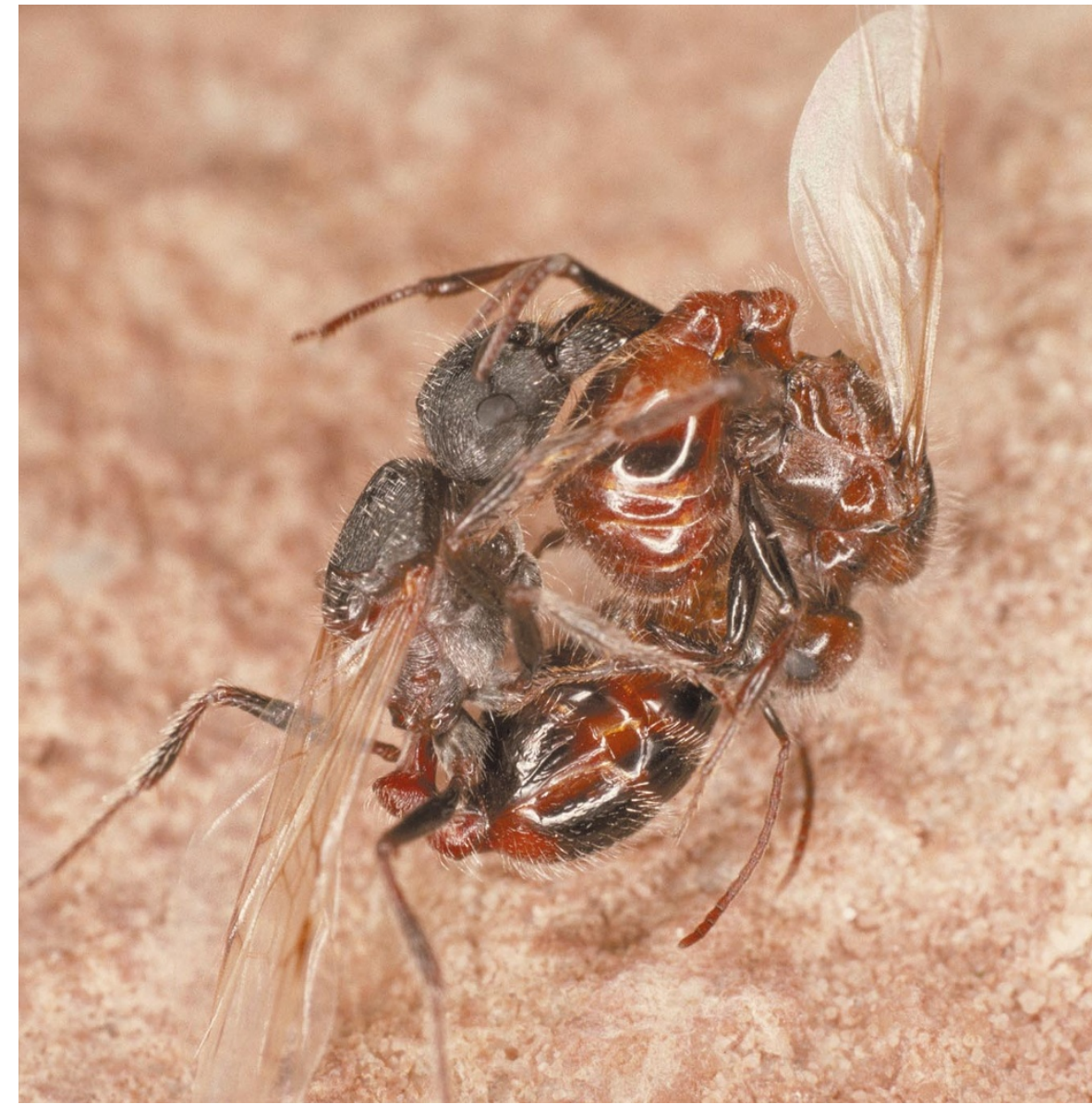

Mating time: ants display enormous variability in reproductive tactics across the 300 ant genera.

much beyond the film Antz, to keep on track and not go astray among the fascinatingly complex universe of social insects.

Those ant novices will be initiated straight to Pogonomyrmex, their foraging strategies, their conflicts with neighbouring colonies and how they make decisions, without the detour to other ants with alternative ways of life. And they will also learn a lot about how all this information is gathered and how researchers cope with the manifold problems that generally make field studies on animal behaviour quite tricky — such as temporal changes in activity patterns or motivation. Ants at Work vividly involves the reader in several ingenious experiments especially designed to overcome these and many other difficulties.

Readers more familiar with ants, however, will occasionally feel somewhat uneasy. Pogonomyrmex is only one of about 300 ant genera and it has a rather specialized ecology and behaviour. Generalizations, such as those made in the introduction that workers of all ants are sterile and new reproductives fly off to mate, unduly oversimplify the enormous variability of reproductive tactics in ants, with wingless sexuals mating in the nest or workers laying both fertilized and unfertilized eggs.

Furthermore, some aspects of ant biology presented to the reader as amazing news have

^๑ 1999 Macmillan Magazines Ltd for a long time and in much detail been known from other ants. It is common knowledge among social insect researchers, for example, that an ant colony operates without any central control, that workers can easily switch from one task to another, and that the meaning of signals used in communication is context-specific. That an ant queen is not in charge, claimed on the book jacket to be a revolution in our thinking on natural organization, is therefore trivial. On the other hand, the remark that no ant has power over another is somewhat puzzling, given the accumulating evidence for overt kin conflict and dominance hierarchies in some ant species.

One of the book's major themes is division of labour, a very acute problem that is being widely (and heatedly) discussed among social-insect researchers and has also elicited considerable interest in the artificialintelligence community. Here, Gordon describes a series of experiments and observations which demonstrate that task allocation is highly flexible and that encounter rates between individuals may be important for task switching in Pogonomyrmex. She then uses this evidence to shatter the alternative hypothesis that an ant's task is innate, that is, that a worker does a single task throughout its life. However, to my knowledge, this latter viewpoint has never been 